\title{
SAMS in Hong Kong Schools: A User Acceptance Audit
}

\author{
A.C.W. Fung and J. Ledesma \\ Department of Education Studies, Hong Kong Baptist University, Renfrew Road, Kowloon, Hong \\ Kong SAR, China \\ Tel: (852)-2339-5679 \\ Fax: (852)-2794-3329 \\ Email: alexfung@hkbu.edu.hk
}

Key words: Educational Management, Research, Management, Administration, Evaluation

Abstract: $\quad$ This paper describes how $\mathrm{SAMS}^{1}$ has been implemented in Hong Kong schools and the degree of usage at the end of the five-year project. Through presentation of quantitative and qualitative findings, the problems faced in implementing SAMS at Hong Kong schools are discussed. The user acceptance audit reveals a low level of use and factors affecting the implementation and usage of the system are reported. Empirical evidence from the study clearly indicates the need for a client-centred approach, both in the design and implementation process, in order to be successful with computerised school information systems (SIS). The future of SAMS is also discussed.

\section{INTRODUCTION}

In Hong Kong, the use of information technology (IT) in education has rapidly expanded over the last two decades. In the early 1980s, computer education was introduced in secondary schools as a new subject in the curriculum. At present, almost all secondary schools offer Computer Literacy to junior form students (ages 12 to 14) and Computer Studies to senior form students (ages 15 to 16). This was further advanced, from a developmental stage to a popularisation stage, in 1993 when the Hong Kong government

${ }^{1}$ SAMs stands for 'School Administration and Management System', a SIS centrally developed by the Education Department of Hong Kong for all schools in the public sector. 
introduced the School Administration and Management System (SAMs) - a centralised, integrated system supporting major administration and management processes, which transmitted electronic information between schools and the Education Department. The current government policy, laid down in 1997, is advocating the use of IT in support of teaching and learning across the curriculum in both primary and secondary schools.

\subsection{Background of the SAMs project}

In 1993, the Education Department of the Hong Kong Government initiated the use of computers in educational management on a territory-wide basis by embarking on a five-year Information Systems Strategy (ISS) aimed at improving the efficiency and effectiveness of Hong Kong education. With an investment of 70 million US dollars, an integrated computer network, linking the Education Department (ED) and all government and aided sector primary and secondary schools, was developed. Under the ISS project a centrally developed and standardised management information system, SAMs, was implemented in all schools. The SAMs consists of twelve core applications and four supporting applications. Each school in the scheme was given a local area network with four or five PC workstations to operate SAMs on the Chinese Windows platform.

\subsection{The theoretical framework of the research}

A review of existing literature (Bjorn-Andersen et al., 1986; Fullan, 1982; Mayntz, 1984; Rogers, 1983; Stasz et al., 1986) has indicated that three variable groups are important in determining the success and impact of implementing computer-assisted school information systems. These factors are: (1) features of the innovation contents, (2) features of the innovating unit, and (3) the innovation strategyused.

Drawing on the above literature, and extending Visscher's (1991) framework, a model was developed that portrays the assumed relationships between a number of variables that have bearing on the use and effects of SAMs (see Figure 1). According to Visscher et al. (1999), the use of SAMs is assumed to be influenced by perceived SAMs quality (block B), the features of the implementation process (block C), and of school organisations (block D). Moreover, the higher the perceived SAMS quality, the more the implementation process promotes SAMs usage; and the more the features of SAMs match the nature of schools, the more intense the use of SAMs (block $\mathrm{E}$ ) is expected to be. Finally, the magnitude and type of use to which SAMs is put are expected to lead to both positive and negative effects (block F). 


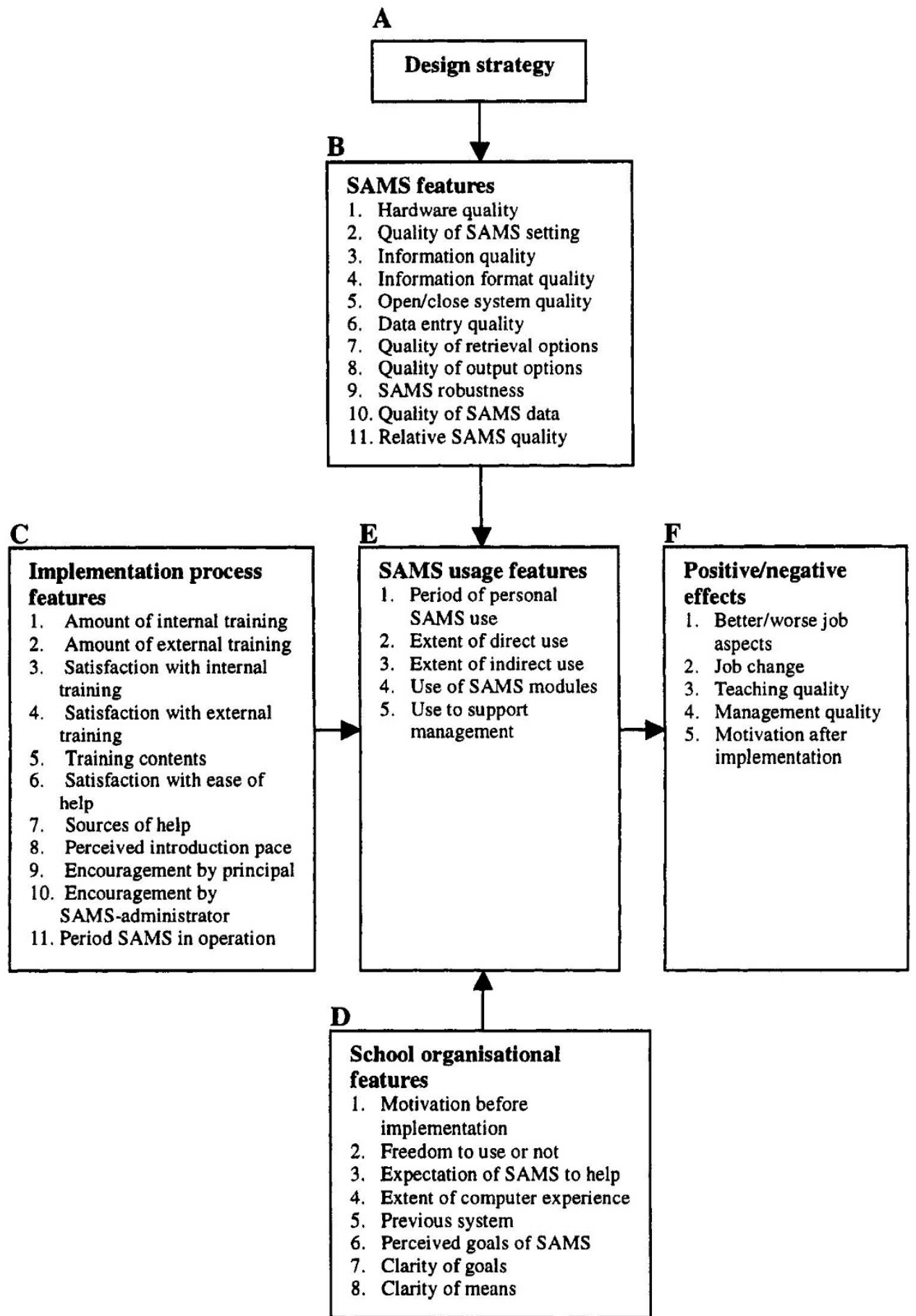

Figure 1. Variables studied and the assumed relationships between the variable groups 


\subsection{The research study}

The comprehensive evaluation of SAMS from its commencement to completion date (1993-1998) was conducted in three phases, using both quantitative questionnaire surveys and a qualitative interview study:

1. Phase I: Quantitative Questionnaire Survey - conducted in late 1996, when SAMS had already been rolled out to half the school population, to provide an indication of the reactions and attitudes on the part of the end-users;

2. Phase II: Qualitative Interview Study-conducted in 1997; and

3. Phase III: QuantitativeQuestionnaire Survey - conducted in late 1998 to document the implementation status of SAMs, modes of use and degree of use over the five full project years.

A thorough discussion of results from the Phase I quantitative survey of the variables from the model has already been published (Visscher et al., 1999). The present paper reports on the Phase II qualitative part of the SAMS evaluation study based on a content analysis of the comments made by the interviewees. Aspects of the interviews are used to elicit users' perceptions of using and implementing SAMs, with data from the Phase III survey included where appropriate. Lessons learnt from the Hong Kong experience, as well as the possible future of SAMs, are discussed in this paper.

\section{RESEARCH METHOD}

\subsection{Data collection}

\subsubsection{Phase I quantitative datacollection}

By mid-November 1996, SAMS had been rolled out to 641 primary and secondary schools. Each school in this population was sent a set of four questionnaires in January 1997: one for the school principal, one for the SAMS administrator, one for a teacher (who was not the SAMS administrator), and one for a clerk/secretary. Each questionnaire consisted of forty-five common questions, while that for the school principal included six additional questions concerning school characteristics and the managerial use of SAMs. The results of that survey indicated that use of SAMs at the time was low (Visscher et al., 1999). 


\subsubsection{Phase II qualitative data collection}

In addition to the quantitative study, a series of semi-structured interviews were carried out. Three sets of interview questionnaires, incorporating significant features identified in the analyses of the survey data, were developed. Fifteen primary and fifteen secondary schools from the total 294 schools that returned the complete set of four questionnaires were then randomly selected. There were four groups ofinterviewees (principal, SAMs administrator, teacher, clerk) from each school. Interviews were conducted in Cantonese. Data were then transcribed and translated into English and analysed using the NUD*IST software. A NUD*IST coding tree was established reflecting the conceptual framework of the qualitative phase (Appendix 1).

The qualitative findings presented in this paper are based on the responses of 120 interviewees from 30 schools, especially the perceptions of the four user groups - principal, teacher, clerk and SAMS administrator - to the following questions:

1. What were the factors that affect (hinder or promote) SAMS usage?

2. What were the users' perceptions on the support provided for SAMS?

3. Suggestions for improvement?

\subsubsection{Phase III quantitative data collection}

At the end of the fifth year, in August 1998, SAMs had been rolled out to almost all primary and secondary schools. A second, shorter questionnaire was distributed to all 1265 government, private and subsidised primary, secondary and special schools. The 32-item bilingual questionnaire consisted of three sections. Section One was about the implementation of SAMs, Section Two was about IT in education in Hong Kong schools, while Section Three was about connecting the SAMS network and the IT in Education network. The questionnaire was answered by the principal or SAMS administrator on behalf of the school.

From the total school population of 1265 in Hong Kong, 961 (76\%) valid questionnaires were received: 607 out of 772 from primary schools $(78.6 \%)$, 306 out of 424 from secondary schools $(72.2 \%)$, and 48 out of 69 from special schools $(69.6 \%)$. SAMS was beingused $84.5 \%$ of the primary schools, $93.5 \%$ of the secondary schools and $95.8 \%$ of the special schools. 


\section{FINDINGS FROM THE PHASE III SURVEY}

Many studies have placed emphasis on the usefulness of IT in managing schools. In Hong Kong, the idea of using SAMS in schools has generated a wide range of responses, varying from resentment towards imposed changes to hopeful optimism about the opportunities that might exist. The study indicated a mixed response from school staff towards the use of SAMs. On one hand, users viewed the system as having design limitations and performance problems, likebeing "too slow... mechanistic and prescriptive". On the other hand, there was a significant positive response which saw SAMS as benefiting school management, particularly in relation to workplace requirements.

\subsection{The extent of SAMS use in Hong Kong schools}

The Phase III survey showed that schools did not necessarily start full operation with all modules in SAMS after theroll-out process, even though all the software modules had been installed. The amount of data input into different modules also varied from one school to another, and only a small number of schools were found to be using all the SAMS modules. In general, the degree of SAMS usage (Table 1) was shown to be on the low side. Use of SAMS by school staff was not yet widespread at the end of the five year project.

Table 1. Use of SAMS modules by schools in 1998/1999

\begin{tabular}{|l|c|c|}
\hline SAMS module in use & $\begin{array}{c}\text { Primary } \\
(\mathbf{n}=\mathbf{5 1 3}) *\end{array}$ & $\begin{array}{c}\text { Secondary } \\
(\mathbf{n}=\mathbf{2 8 6}) *\end{array}$ \\
\hline School Management & $448(87.3 \%)$ & $255(89.2 \%)$ \\
\hline Student & $466(90.8 \%)$ & $264(92.3 \%)$ \\
\hline Student Assessment & $307(59.8 \%)$ & $210(73.4 \%)$ \\
\hline Student Attendance & $141(27.5 \%)$ & $118(41.3 \%)$ \\
\hline Staff & $448(87.3 \%)$ & $228(79.7 \%)$ \\
\hline Staff Deployment & $80(15.6 \%)$ & $78(27.3 \%)$ \\
\hline Timetabling & $112(21.8 \%)$ & $144(50.3 \%)$ \\
\hline Data Management & $349(68.0 \%)$ & $228(79.7 \%)$ \\
\hline Allocation & $122(23.8 \%)$ & $160(55.9 \%)$ \\
\hline HKEA & $9(1.8 \%)$ & $182(63.6 \%)$ \\
\hline FMP & $17(3.3 \%)$ & $39(13.6 \%)$ \\
\hline Programme Scheduling & $23(4.5 \%)$ & $30(10.5 \%)$ \\
\hline Special Education & $2(0.4 \%)$ & $1(0.3 \%)$ \\
\hline CDS & $456(88.9 \%)$ & $272(95.1 \%)$ \\
\hline
\end{tabular}

* Data based on schools with SAMS installed 


\subsection{Users' satisfaction with SAMS}

According to the research model shown in Figure 1, use of SAMs is assumed to be influenced by the perceived SAMS quality (block B). An essential question in the survey, therefore, was to ask schools about their overall level of satisfaction with the system. The study revealed that $62.2 \%$ of the primary schools (with a mean value of 2.38 and standard deviation of 0.62 ), and $72.6 \%$ of the secondary schools $(2.250 .89)$ were satisfied with the system (Table 2$)$.

Table 2. Overall level of satisfaction with SAMS

\begin{tabular}{|l|c|c|}
\hline Level of satisfaction & $\begin{array}{c}\text { Primary } \\
(\mathbf{n = 5 1 3 )}\end{array}$ & $\begin{array}{c}\text { Secondary } \\
(\mathbf{n = 2 8 6})\end{array}$ \\
\hline [1] Very satisfactory & $12(3.2 \%)$ & $11(3.8 \%)$ \\
\hline [2] Satisfactory & $185(36.1 \%)$ & $153(53.5 \%)$ \\
\hline [3] Unsatisfactory & $109(21.2 \%)$ & $57(19.9 \%)$ \\
\hline [4] Very Unsatisfactory & $11(2.1)$ & $5(1.7 \%)$ \\
\hline Total & $317(61.8 \%)$ & $226(79.0 \%)$ \\
\hline Missing & $196(38.2 \%)$ & $60(21.0 \%)$ \\
\hline Grand Total & $513(100.0 \%)$ & $286(100.0 \%)$ \\
\hline
\end{tabular}

\subsection{Users' difficulties in implementing SAMS}

In the Phase III survey, schools were asked to indicate the five most difficult aspects in their SAMS implementation from a list of about 20 items. Table 3 is a summary of the difficulties encountered by schools in implementing SAMs. For both primary and secondary schools, these issues are related to questions of:

- Technical manpower within the school;

- External support for troubleshooting;

- System flexibility;

- Hardware performance and adequate equipment;

- Functions not meeting school needs: and

- Training.

\begin{tabular}{|l|l|}
\hline Primary Schools & Secondary Schools \\
\hline Not enough technical manpower in school $(67.3 \%)$ & Low hardware performance $(82.5 \%)$ \\
\hline Insufficient external support for troubleshooting $(60.4 \%)$ & System not flexible enough $(66.1 \%)$ \\
\hline Low hard ware performance $(56.5 \%)$ & Insufficient number of workstations $(49.7 \%)$ \\
\hline System not flexible enough $(43.3 \%)$ & SAMS functions not meeting school needs $(46.2 \%)$ \\
\hline Inadequate training by the ED $(41.3 \%)$ & Not enough technical manpower in school $(45.1 \%)$ \\
\hline
\end{tabular}




\section{FINDINGS FROM THE QUALITATIVE INTERVIEWS}

All the concerns revealed in the Phase III quantitative survey were also identified in the Phase II qualitative study. Findings from the interviews provided a deeper understanding of the factors that affect the success of a large-scale implementation of a school MIS (Management Information System) such as SAMs.

\subsection{Factors that promote the use of SAMS}

Variables for promoting the introduction and use of SAMS included direct motivation (i.e. the role of the Education Department and principals) and indirect motivation (i.e. self-motivation to use the system).

\subsubsection{Direct motivation}

Direct encouragement from the Education Department was seen as the primary factor in promoting the introduction and use of SAMS. In this regard, the ED adopted the strategy of not mailing circulars to school but instead using the communication and delivery system(CDS) function in SAMS. As a result, this is the SAMS function picked up by the largest number of schools. Another form of direct motivation seen by some schools was simply the provision of extra computers.

"We know that if we join SAMS, we will be provided with some computers" (SAMS administrator interview, 1997).

Some staffalso mentioned encouragement from the school (especially from senior people such as the principals) to use the system, as being a strong factor. To some teachers, there was pressure to use the system. They felt they were forced to use it whether they liked it or not. One teacher mentioned that the motivation to use the system depend a lot on how the principal viewed the system. If the principal thought there was a need for change, then teachers would not object. But if s/he thought that the system was useless, then the staff would also feel the same way.

"It is very important to provide orientation to the users (teachers and clerical supports). You need to show them the advantages ofusing the system, such as what will be the end-product and how will they benefit from using the system" (principal interview, 1997). 


\subsubsection{Indirect motivation}

'Acceptance by staff' was considered a factor that promoted the use of SAMS. Most respondents strongly believed that the SAMS system was a good computer system for administrative support. In fact, they had a very positive attitude towards its impact and benefits to schools. They also felt that the system could provide more systematic and accurate data storage, resulting in better quality information. One clerk remarked, "Having a systematic and organised database will not only ensure completeness of data, it will also provide convenience in retrieval of such data" (clerk interview, 1997).

Another factor was the 'ease of use' of the system. 'No increase in workload' and a 'felt need to use' the system were also equally important. As one staff commented, "We all feel that the system can help us. That is why we are very eager to use it" (clerk interview, 1997).

Some schools were lucky enough to have a computer teacher familiar with programming. 'Having the right person' who could handle the system was perceived to be important since s/he took up all the workload, thus alleviating the work of the other staff members. Most of the SAMS administrators were computer teachers, hence they have not objected to such a system. In fact, they invested a lot of their time and effort in the system management. As one clerk has mentioned, "I believe having the right person is a factor. If we don't have this person, I think we won't be able to implement the system as fast as we have done" (clerk interview, 1997).

'School expectation' was also one of the reasons for using SAMS. In fact, some schools were so computer-oriented that they were using computers in administration as early as 1988 . Having a system that aligns with the direction that they want to pursue explains why these schools were keen on using SAMs. In most instances, schools were expecting SAMS to help in clerical tasks, accounts, report cards and other daily operations. Other comments provided were:

"I think we all have a very high expectation on the system. We all hope that this system can help us manage and administer the school operations."

"We expect the system to efficiently support us with our school management efforts."

"We need SAMS mainly for administrative support. We hope that the system will be able to develop our school operational system." 


\subsection{Factors that hinder the implementation and use of SAMS}

Many factors were identified as hindrances to the implementation of SAMS in schools. These include, without any order of priority: unwillingness to transfer (to abandon existing systems), staff resistance, felt need for change, school readiness, system reliability and hardware performance, system design, and system support. The following sections explain the reasons behind these factors, from the users' perspective.

\subsubsection{Unwillingness to transfer (to abandon existing system)}

A prime reason for the low use of SAMS was the unwillingness of schools to abandon their current computerised system. Satisfaction was perceived to be crucial. Most staffs were satisfied with their existing system, so they felt there was no need to change to a new one (in this case, SAMS). Schools with a more familiar tailor-made computerised system of their own did not have the urge to use SAMS at all. Schools without any previous computer system tended to use SAMS more. Although the hardware and software were provided free to schools by the government, there was no policy of mandating the use of SAMS. Schools had a choice of using or not using the system. The lack of necessity and applicability of SAMS as perceived by schools has definitely hampered the degree of use.

One SAMS administrator commented that the tendency for staff members was to use their own system instead of the SAMS system since they are used to it, find it very convenient and relatively easy to use. Most importantly, they think their own system can meet their school needs and is $100 \%$ accurate and reliable.

\subsubsection{Staff resistance}

Some of the older teachers (the key factor being age) were quite afraid of using the computer. They were also afraid of using SAMS because they feared that they might corrupt the data. This can be explained easily by their lack of computer knowledge. In most instances, most of them were not willing or were not yet able to handle the responsibility. Resistance to using the computer was seen as an important factor. As one principal stated:

"Younger teachers are more computer-literate than the older teachers who are not so well-equipped. The ED should try to offer more training; at the moment it is not enough. If we don't have enough training, then obviously SAMS usage will be low" (principal interview, 1997). 
Perhaps it is the level of computer knowledge of staff, rather than age, that is the problem. Schools with more computer-literate teachers found it easier to promote the use of SAMS. Teachers who were familiar with computers were also more eager to take up the responsibility of SAMS administrator. They were also seen as valuable asset in troubleshooting and problem solving. Undoubtedly, teachers with less or no computer knowledge were using the system less.

The attitude of stafftowards SAMS was also a contributing factor. SAMS administrators, teachers, principals or clerks who did not feel the need to use SAMS would not bother to use it at all. This lack of motivation, as well as a lack of time and a heavy workload among teachers, led to the low use of SAMS.

\subsubsection{Felt need for change}

In some schools where staffefficiency and staffperformance (staffappraisal) were given high priority, teachers were very eager to learn since they had to come out with acceptable performance. But for some schools, staff members were not required to use SAMS; only the SAMS team members (normally a group of five teachers and clerks) handled the system. In these schools, apart from the team, no one else was using the system. Since it was not a requirement for teachers to use it, they did not make any effort to learn.

"If the Education Department forces schools to change, then everybody will change whether they like it or not. If there is no pressure, then nothing will change even 100 years from now. Schools who are comfortable with their present system will not bother to take any action to change" (principal interview, 1997).

\subsubsection{School readiness}

School readiness was another factor contributing to the low degree of SAMS use. The majority of the schools were unclear on the applications and goals of SAMS. Some schools stressed that 'having the right person' was important while others mentioned that their SAMS administrator was not ready yet. Most staff members have not undertaken any training at all. Some schools were hesitant of trying for fear of corrupting their data while others lacked confidence. Some schools lacked support (manpower), resources (insufficient workstations) and facilities (space) while others did not have the time to set up the system at all. 


\subsubsection{System reliability and hardware performance}

System reliability and system support were also seen as crucial factors. Due to frequent system breakdown, some schools started to lose faith in the system. They developed some hesitation in using the system. A couple of schools had indicated they were abandoning SAMS and reverting to their old computer system instead.

A number of system problems were reported during the interviews. For example, some schools have encountered problems with server breakdown due to 'fuse-jumping'. Others had problems with 'bugs'. The support for both hardware (by vendors) and software (by the ED) was perceived as grossly inadequate. The heavy workload and time schedule of the teachers meant they did not have the time to fix any problems or learn the system. Even if they wanted to learn, it would still affect the classes they were teaching, and so the performance of their students.

The majority of the users were disappointed with the hardware performance. None of the schools interviewed found the system speed acceptable. All the respondents commented that the system was slow, and the system configuration (server speed, insufficient RAM, small hard disk space) was not able to support the large SAMS database (especially with Chinese data entry), which led to a slow input/output response time. The system was also found by some users to be unstable. There were cases of data loss, whether due to system or operation error, and the users were unable to trace backrecords entered. Sometimes data mismatch also occurred("What SAMS produces is not what we need," said one clerk). Some schools also reported a high frequency of system breakdown. One school encountered system breakdown almost once every three days. According to one teacher, "The system will come up with some unreadable fonts/silly characters. Sometimes for no reason at all, the computer operation will suddenly 'hang' (suspend)."

\subsubsection{System design}

There was strong agreement among interviewees that the major hindrance in the introduction and use of SAMS was the users' satisfaction with the system design. A main dissatisfaction with the system design was its 'complicated data entry method' and the system was considered inconvenient and troublesome. As one teacher remarked, "The navigation set-up is not straightforward. There are so many procedures to follow before one can proceed. That's why a lot of my colleagues find this system unattractive."

Many commented that the system lacks flexibility, while others regretted that too many upgrade versions were necessary during their implementation. Another drawback of the system design was that only a limited number of past 
years' records werekept on the SAMS server; the rest had to be archived onto backup diskettes or tapes. As one teacher said, "The system is very inefficient. I can't retrieve the testimonial of a student who graduated five years ago from the current workstation. I have to go back to our back-up diskettes. It is faster to check from our manual filing system. So what is the use of SAMS then?"

\subsubsection{System support}

According to the findings in the Phase III survey, most schools found the efficiency and quality of the support provided for SAMS to be unsatisfactory. These user perceptions are shown in Table 4.

Table 4. Level of satisfaction with the support provided

\begin{tabular}{|c|c|c|}
\hline Level of Satisfaction & $\begin{array}{c}\text { Primary Schools } \\
\text { Mean } \pm \text { SD }\end{array}$ & $\begin{array}{c}\text { Secondary Schools } \\
\text { Mean } \pm \text { SD }\end{array}$ \\
\hline EFFICIENCY & \\
\hline S A M S support by the ED & $2.69 \pm 0.67$ & $2.42 \pm 0.81$ \\
\hline Hardware/network support by vendor & $2.58 \pm 0.66$ & $2.50 \pm 0.69$ \\
\hline \multicolumn{2}{|l|}{} & $2.41 \pm 0.71$ \\
\hline SAMS support by the ED & $2.58 \pm 0.67$ & $2.39 \pm 0.61$ \\
\hline Hardware/network support by vendor & $2.53 \pm 0.63$ & \\
\hline
\end{tabular}

Support for SAMS included hotline support and hardware support, as well as user manual support. The interviews provided more detailed information about these from the users' perspective.

\subsubsection{Hotline support}

The responses on the hotline support provided by the Education Department were diverse. Several schools felt the efficiency of the operator and the speed of response were acceptable. Others also commented on the willingness and dedication of the operators to help solve their problems.

To others, however, hotline support was not at all satisfactory. "The line was always engaged" was a common observation made by most users. Others experienced unanswered phonecalls during office hours; someneeded to wait for a long time before they got connected. When they did, operators just took down their contact details and didn't always return the calls.

One of the frustrations noted was the slow response. The waiting period was too long: responses come one month after the requests, sometimes even longer. Some information was not easily accessible; there was no provision for a prompt and correctreply. Others had to do a lot of follow-up, yet they did not get the right answers or help. Clerks mentioned that it is faster to ask the SAMS administrator or other computer teachers than to call the hotline. 
Hotline operators' lack of computer knowledge was another concern for most schools. The operators did not know anything about SAMS programming; most of them were just receptionists in charge of taking messages. As a consequence, callers needed to repeat their problems at least five times before they got to the right person. Operators would refer them from one colleague to another, which was not only time consuming and frustrating but also a reflection of the inefficiency of the support provided.

"I called up the hotline because we needed to change a setting in a certain platform. The operator doesn't know the answer so he passed me to a colleague who is also unsure of the procedures. I was told not to touch anything, make a back-up set, have it delivered to their Hong Kong office and wait for three days. The diskette came back with no changes except for one particular field. My initial reaction was that the whole process was a waste of time. Instead of sending somebody to our school to fix the system, it took them longer to work it out. I know that they are very concerned with security, but this is not an efficient way of working. If hotline support is efficient, then why bother to send somebody up to their office?" (SAMS administrator interview, 1997).

\subsubsection{Hardware support}

Not only were most users dissatisfied with the hotline support, they were also dissatisfied with the external support provided by the hardware vendor. Some interviewees considered the vendor irresponsible, hesitant and undedicated.

"External support takes a long time to arrive at schools. We'd call them up a few times, but they are very hesitant to come. Their level of service is unacceptable. Instead of fixing the problem, they just look at the system, open an order number and tell you to wait for their next visit. When they come again, they'll give you another order number. In this way, they could charge the ED twice. But the problem still exists. They haven't solved anything" (SAMs administrator interview, 1997).

"We are finding it inconvenient as it affects daily administrative tasks. Sometimes we can't use the system for weeks. We can't totally rely on SAMS which is why we are still keeping our old system as an alternative. If the ED can ensure in the future that the system is reliable enough, then perhaps we will consider replacing our old system" (principal interview, 1997). 


\subsubsection{User manual support}

A small number of schools thought the manual was good. They liked its bilingual nature, and felt it had sufficient information and a detailed explanation of the procedures.

On the contrary, the majority of users found the manual troublesome and poorly written. It did not explain the internal structure of the system (for security reasons), and users had difficulty finding the information they needed. The content of the manual was seen to be very procedural as it only provided general information with nothing on trouble shooting.

Only a few found the booklet providing a summary of the manual useful. Most teachers found it very frustrating to read the manuals because they did not offer any suggestions. Considering their limited time and heavy workload, teachers preferred trying out the system instead of reading the manuals. As one clerk said, "You have to attend courses to understand it. You also have to use the system before you know what is being said. Overall speaking, you need time to master it."

\subsubsection{SAMS training}

Training is undoubtedly a crucial factor affecting the implementation anduse of SAMS. When asked in the Phase III survey about the level of satisfaction with the training provided, the following feedback from users was noted (see Table 5).

Table 5. School satisfaction with the training provided

\begin{tabular}{|l|c|c|}
\hline Level of Satisfaction & $\begin{array}{c}\text { Primary Schools } \\
\text { Mean } \pm \text { SD }\end{array}$ & $\begin{array}{c}\text { Secondary Schools } \\
\text { Mean } \pm \text { SD }\end{array}$ \\
\hline Quantity of training & $2.57 \pm 0.64$ & $2.20 \pm 0.68$ \\
\hline Quality of training & $2.45 \pm 0.60$ & $2.31 \pm 0.59$ \\
\hline Timing of training & $2.70 \pm 0.71$ & $2.33 \pm 0.82$ \\
\hline Mode of training & $2.55 \pm 0.65$ & $2.21 \pm 0.69$ \\
\hline
\end{tabular}

The interviews solicited a number of positive comments related to ]SAMS training, for example:

- Staff without previous knowledge of SAMS gained confidence in trying the system after attending training courses.

- Users believed that the training had helped them understand the principle or rationale of the system.

- Some users had a much increased desire to practise what they had learned. 
- Others welcomed the idea of a stand-alone version since they could combine their existing data with SAMS data.

- Others were also satisfied with the trainers.

On the negative side, those dissatisfied with the quality of the training provided commented that:

- The training sessions were too fast or too slow, too detailed or too brief, frequently repetitive and superficial.

- The training courses were not tailor-made to meet the varying standards of the audiences. A teacher familiar with SAMS will find the training too simple and boring, while a novice teacher will find it difficult to comprehend.

- The sessions did not cater to individual school needs. Some believed it was too technical and not tailor-made for the individual school setting, while others found it below standard. In fact, a user commented that it was a waste of time attending the training courses.

- The trainers were unfamiliar with what they were teaching. Most of the topics were very general and taught according to the books; trainers were not able to provide an in-depth description of SAMS

- Others found the training to be very operational, with little or no hands-on exercises. As one SAMS administrator said, "I wanted to know what happens to the data, where it goes and how I will retrieve it again. It would be good to have an idea of how the whole system functions."

There were also concerns raised about the insufficient number of training sessions and the limited trainee quota allocated to schools. The ED was seen to be putting very low priority on the training of staff, especially in allocating a quota for staff to attend training. According to some schools, even if they wanted to send more people, they were still limited by the quota allocated to them. Most respondents strongly believed that the ED should send trainers to schools for maximum benefits. Since not all teachers would have the chance to attend the training, sending trainers to schools was seen as the solution to the problem.

The timing and duration of training were seen as both unsuitable and too tight; some preferred to have intensive training for three weeks or more while others thought the duration of the workshop was too long. Others suggested having training courses on an ongoing basis, especially for new users. One SAMS administrator said:

"There is a high yearly staff turnover. To ensure continuity in operation, training courses must be continuously provided to schools. This will also lessen the responsibility of the SAMS administrator since 
more people will know how to operate the system, hence there will be some sharing of workload" (SAMS administrator interview, 1997).

In order to fill up the limited training quota provided by the ED, while coping with the hectic teaching schedule at schools, most schools nominated different staff members to attend different SAMS training sessions. Some interviewees pointed out that such a practice of sending just anybody to attend training is unrealistic and has detrimental effects.

"I attended a one-day workshop, which is about data entry of students' details; my other colleague attended another part of the workshop. When I attended the training, I don't actually know what was going on. I was asked to attend the training, so I went" (clerk interview, 1997).

\subsection{Users' suggestions for improvement}

In general, the majority ofusers said they accepted the philosophy of using IT in support of managing schools. To achieve such objectives with SAMS, however, improvements must be made regarding both the effectiveness ofthe system and the effectiveness of the support.

\subsubsection{Effectiveness of the system}

Respondents strongly indicated that user-friendliness and flexibility in the system were important factors forensuring success in SAMS implementation and usage. Many users felt that there were unnecessary steps in data record entry and retrieval that could have been avoided, for example, by using a 'browse-mode' or 'form-filling' procedure. Others pointed out that the system was very tedious to use at times, as it does not have a cut/copy/paste function, and did not allow deletion of sections within a record.

As one user stated, "The whole design makes data entry and retrieval difficult. Why can't they have all the record of a particular student in one file? I have to save, exit, add, save, exit, add etc.. . it's very time consuming. There are too many buttons to press. I think they need to think about the whole navigation process."

Most schools indicated they would have to upgrade the system, increase the server memory and use more powerful computers to suit their needs. Some schools even showed a willingness to pay and upgrade the system by themselves, but the Education Department was not supportive of the idea as that would complicate maintenance and support for such non-standard equipment. 


\subsubsection{Effectiveness of the support}

According to most schools, the Education Department should not assume that schools no longer need help once their teachers have joined the training courses. It is impossible to totally rely on one person (or even a team) to run SAMS. The Education Department must also ensure that the quality of the training is up to standard and expectation, and must take into consideration the time and effort demanded from the teachers.

Most schools recommended that the ED provide resources (substitution) to cover teachers on SAMS training courses; and provide an additional system supervisor at each school instead of having a teacher take up the SAMS administrator responsibility. Schools also recommended that the ED send trainers to conduct on-site training at the schools, rather than having different teachers sent to be trained in different modules at external courses.

This feedback is illustrative of the kind of improvements that school users in general expect of SAMS. In the summative evaluation of the Phase III survey, much the same result was obtained when schools were asked to identify the five areas in most need of improvement (see Table 6, percentages are schools identifying specific items ofconcern).

Table 6. The five areas most in need ofimprovement in SAMS

\begin{tabular}{|l|l|}
\hline Primary Schools & Secondary Schools \\
\hline Improve hardware performance $(55.8 \%)$ & Improve hardware performance $(78.7 \%)$ \\
\hline Effective hotline support $(52.2 \%)$ & Increase system flexibility $(64.0 \%)$ \\
\hline Increase system flexibility $(44.6 \%)$ & More workstations $(54.5 \%)$ \\
\hline $\begin{array}{l}\text { More training and support for add-on } \\
\text { program development }(43.7 \%)\end{array}$ & Match with user requirements $(50.3 \%)$ \\
\hline More internal training $(38.0 \%)$ & Effective hotline support $(37.4 \%)$ \\
\hline
\end{tabular}

\section{CONCLUSION}

This paper has described and discussed many issues about the design and implementation of SAMS in Hong Kong schools. At the end of 1998, when the five-year project was completed, the data suggested that system use was still very limited and tended to be of an administrative rather than managerial nature in schools. The study also revealed various constraints existing in most schools thatadversely affected SAMS use. A crucial element cutting across all these limiting factors appears to be the lack of a client-centred approach in both the design and implementation process. Future SIS projects can learn from the Hong Kong experience in all phases, including design, development, implementation and maintenance (training and support). 
Most of the teachers interviewed believed that the introduction of information technology at the classroom or school level has the potential to substantially change their day-to-day working life. Some were of the opinion that front-line teachers should be involved in all aspects of system development since this would produce a system that would be far more likely to benefit schools, teachers and students. They also stressed that such systems must reflect and support the operating rhythms of the school, allowing more flexibility in daily operations. Unfortunately, SAMS failed to cater for such needs, as characterised by its rigid, standardised operating procedures. The large-scale implementation of SAMS has been an ambitious computerisation project. Whether schools are willing to replace their individual systems depends much on the design of SAMS and how well it is being implemented (Fung,1996).

\subsection{The future of SAMS}

There is no doubt that the Education Department intended the SAMS project to improve school management effectiveness and efficiency. Irrespective of the difficulties encountered, the experience of schools with SAMS was as a building block to more successful institutional improvement through IT in educational management. Under the current government policy of integrating IT in support of teaching and learning at schools, there is the need for schools not only to better manage with IT, but also to better manage through IT.

Although the five-year project has already come to an end, it is envisaged that SAMS will not be discarded as the innovation cannot be reversed, nor can it be left stagnant as it is. On-going development is a necessity, and such development (or re-development) should be done with thought to the educational needs of the schools, as well as the technological advances of IT. As schools in Hong Kong are moving down the road of self-management according the Education Commission's ECR7 recommendation, the future SAMS would be expected to provide not only improved administrative functions, but also support for school policy and decision-making. While school improvement is being advocated under the school-based management policy, it would be reasonable to expect that the future SAMS would support school-based self-evaluation. The system designers must be prepared to adopt such a client-centred approach in order that the future SAMS truly is an administrative and management system that is welcomed by schools.

Over the past five years, technological advances have surpassed the hardware (some schools still use 486 machines) and system platform (Windows 3.1) of SAMS. In the age of the Internet, communication and connectivity is the key to success and the future SAMS will definitely have to 
be developed with web-based technology. Function-wise, it will also have to be developed to support the integration of teaching and learning using ICT.

In terms of sustainability, the concept of SAMS as centrally funded, developed and supported has to be re-visited. The bureaucratic model is simply not flexible enough to meet the fast changing needs of schools. Apparently some senior officials in the Information Systems Division of the ED have already recognised this and there is a likelihood that future SAMS development will be opened up to market competition. This is in line also with the decentralisation of funding to schools in the school-based management initiative. Hopefully, in the not too distant future, schools will find suites of SIS programs on the market which they can choose to meet their needs.

\section{REFERENCES}

Bjorn-Andersen, N., Eason, K., \& Robey, D. (1986). Managing computer impact. New Jersey: Ablex.

Fullan, M. (1982). The meaning of educational change. New York: Teachers College Press.

Fung, A.C.W. (1997). Development of information technology in Hong Kong education over the past decade. In G. Marshall, \& M. Ruohonen (Eds.), Capacity building for IT in education in developing countries. London: Chapman \& Hall.

Hsu, S.H. (1995). Case study of the Information Systems Strategy (ISS) of the Hong Kong Education Department. In B.Z. Barta, M. Telem, \& Y. Gev (Eds.), Information technology in educational management. London: Chapman \& Hall.

Ip Tsang, B.C.H., \& Lee, S.Y.F. (1996). Implementation of the School Administration and Management System: A Hong Kong experience. In A.C.W. Fung, A.J. Visscher, B.Z. Barta, \& D.C.B. Teather (Eds.), Information technology in educational managementfor the schools of thefuture. London: Chapman \& Hall.

Keen, P.G.W. (1981). Information systems and organisational change. Communications of the $A C M, 24(1), 24-33$.

Mayntz, R. (1984). Information systems and organisational effectiveness: The social perspective. In T. Bemelemans (Ed.), Beyond productivity information systems development for organisational effectiveness. Chichester: John Wiley.

Rogers, E.M. (1983). Diffusion of innovations. New York: Nichols.

Stasz, C., Bikson, T.K., \& Shapiro, N.Z. (1986). Assessing the forest service's implementation of an agencywide information system: An exploratory study. Santa Monica, CA: Rand.

Visscher, A.J. (1991). School administrative computing: A framework for analysis. Journal of Research on Computing in Education, 24 (1), 1-16.

Visscher, A.J. (1996). Information technology in educational management as an emerging discipline. International Journal of Educational Research, 25 (4), 291-296.

Visscher, A.J., Fung, A.C.W., \& Wild, P. (1999). The evaluation of the large scale implementation of a computer-assisted management information system in Hong Kong schools. Studies in Educational Evaluation, 25, 11-31. 
Appendix 1

\section{The conceptual framework of the study - NUD*IST coding tree}

(1) /BaseData

(1 1) /BaseData/SchoolType

(1 11 1 $)$ /Base Data/School Type/Catholic

(1 11 2) /Base Data/School Type/State

(1 113 ) /Base Data/School Type/Secondary

(1 114 ) /Base Data/School Type/Primary

(1 1 5) /Base Data/School Type/College

(1 1 6) /Base Data/School Type/Middle

(1 1 7 7 ) /Base Data/School Type/Tech

(1 2) /BaseData/Respondent

(1 $\left.\begin{array}{lll}1 & 2 & 1\end{array}\right)$ /Base Data/Respondent/Clerk

(1 $\left.\begin{array}{ll}1 & 2\end{array}\right)$ /Base Data/Respondent/TechnicalAdministrator

(1 2 2 3 $)$ /Base Data/Respondent/Deputy Principal

(1 2 4) /Base Data/Respondent/Principal

(2) /Motivation

(2 1) /Motivation/Before

(2 2) /Motivation/Now

(2 3) /Motivation/Unmotivated

(2 4) /Motivation/Motivated

(2 5) /Motivation/Neutral

(26) /Motivation/Don'tKnow

(3) /Open Ended Questions

(3 1) /Open Ended Question/First Response

(3 2) /Open Ended Questions/Second Response

(3 3) /Open Ended Question/Third Response

(4) /Amplementation

(4 1) /Implementation/Encouragement

(4 11 1) /Implementation/Encouragement/From Principal

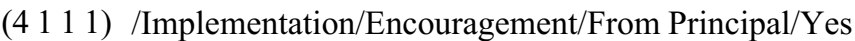

(4 $\left.\begin{array}{lll}1 & 1 & 2\end{array}\right)$ /Implementation/Encouragement/FromPrincipal/No

(4 2) /Implementation/Support

(4 2 1) /Implementation/Support/Hot Line

(4 2 2) /Implementation/Support/Manuals

(4 222 1) /Implementation/Support/Manuals/Reasons

(4 $\left.\begin{array}{llll}2 & 2 & 1 & 1\end{array}\right)$ /Implementation/Support/Manuals/Reasons/No Exercises

(4 2 3) /Implementation/Support/Satisfactory

(4 2 4) /Implementation/Support/Unsatisfactory

(4 2 5) /Implementation/Support/Neutral

(4 3) /Implementation/Goals of SAMS 
(4 3 1) /Implementation/Goals of SAMS/Informed

(4 3 2) )/Implementation/Goals of SAMS/Not Informed

(4 33 ) $/$ Implementation/Goals of SAMS/How

(4 3 4) /Implementation/Goals of SAMS/Your feelings

(4 3 5) /Implementation/Goals of SAMS/Clarity

(4 36 ) /Implementation/Goals of SAMS/Compatibility

(4 37 ) $/$ Implementation/Goals of SAMS/High

(4 3 8) /Implementation/Goals of SAMS/Low

(4 4) /Implementation/Factors

(4 4 1) /Implementation/Factors/Hindered

(4 $\left.\begin{array}{llll}4 & 1 & 1\end{array}\right)$ /Implementation/Factors/Hindered/Work Stations

(4 $\left.\begin{array}{llll}4 & 1 & 1 & 1\end{array}\right)$ /Implementation/Factors/Hindered/Work Stations/ Insufficient

(4 $\left.4 \begin{array}{lll}4 & 1 & 2\end{array}\right)$ /Implementation/Factors/Hindered/Bugs

(4 4 2) /Implementation/Factors/Introduction

(4 4 3) $/$ Implementation/Factors/Promoted

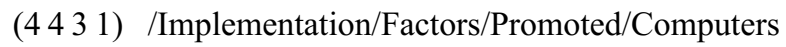

(4 $\left.4 \begin{array}{ll}4 & 3\end{array}\right)$ /Implementation/Factors/Promoted/Directed

(4 $\left.4 \begin{array}{llll}4 & 3 & 2 & 1\end{array}\right) \quad / \mathrm{lmplementation/Factors/Promoted/Directed/Principal}$

(4 $\left.\begin{array}{llll}4 & 3 & 2 & 2\end{array}\right) \quad$ /Implementation/Factors/Promoted/Directed/Ed .Dept.

(4 4 4) /Implementation/Factors/Use

(4 4 5) /Implementation/Factors/Student Information

(4 4 6) /Implementation/Factors/Student Assessment

(4 4 7) /Implementation/Factors/School Management

(4 4 8) /Implementation/Factors/ED Directive

(4 4 9) /Implementation/Factors/Staff Motivation

(4 4 10) /Implementation/Factors/Inconvenience

(4 4 11) /Implementation/Factors/Codes Password

(4 4 12) /Implementation/Factors/Incomplete System

(4 4 13) /Implementation/Factors/Convenience

(45) /Implementation/How

(5) /Quality

(5 1) /Quality/Ease of Use

(5 2) /Quality/Good

(5 3) /Quality/functionality

(5 $\left.\begin{array}{lll}5 & 3\end{array}\right)$ /Quality/functionality/Irrelevant

(5311) /Quality/functionality/Irrelevant/Yes

(5312) /Quality/functionality/Irrelevant/No

(5 $\left.\begin{array}{lll}5 & 2\end{array}\right)$ /Quality/functionality/Missing functionality

(5 $\left.\begin{array}{lll}5 & 3\end{array}\right)$ /Quality/functionality/Navigation

(5 $\left.\begin{array}{lll}5 & 3 & 4\end{array}\right) /$ Quality/functionality/Retrieval

(5 35 5) /Quality/functionality/Data Entry 
(5 3 7) /Quality/functionality/Reliability

(5 $\left.\begin{array}{lll}5 & 8\end{array}\right)$ /Quality/functionality/Use

(5 3 9) /Quality/functionality/School Functions

(5 3 10)/Quality/functionality/Curriculum Planning

(5 3 11)/Quality/functionality/Utilisation of Resources

(5 3 12)/Quality/functionality/Yes

(5 3 13)/Quality/functionality/No

(5 3 14)/Quality/functionality/Reasons

(5 3 14 1) /Quality/functionality/Reasons/Hardware

(5 3 15)/Quality/functionality/Improve

(5 3 16)/Quality/functionality/Not Improve

(5 3 17)/Quality/functionality/Easy

(5 3 18)/Quality/functionality/Not Easy

(5 3 19)/Quality/functionality/Responsiveness

(5 3 19 1) /Quality/functionality/Responsiveness/Hardware

(5 319 2) /Quality/functionality/Responsiveness/Limitations

(5 3 20)/Quality/functionality/Relevant Information

(5 3 21)/Quality/functionality/Fast

(5 3 22) /Quality/functionality/Slow

(5 4) /Quality/Not Good

(5 5) /Quality/Ease of Learning

(5 6) /Quality/Training

(5 6 1) /Quality/Training/Quality

(5 6 2) /Quality/Training/Quantity

(5 63 ) /Quality/Training/Type

(5 6 4) /Quality/Training/High

(5 65 ) /Quality/Training/Low

(5 6 6) /Quality/Training/Not Appropriate

(5 6 7) /Quality/Training/Appropriate

(5 7) /Quality/Management Support

(5 8) /Quality/Communication Links

(5 8 1) /Quality/Communication Links/HK Exam Authority

(5 8 2) /Quality/Communication Links/Educ. Dept.

(5 8 3) /Quality/Communication Links/Curriculum Development

(5 8 4) /Quality/Communication Links/Primary Schools

(5 9) /Quality/Recording

(6) /Usage

(6 1) /Usage/Users

(6 2) /Usage/Non-Users

(6 3) /Usage/Clerks

(64)/UsageReasons 
(6 4 1) /Usage/Reasons/Most Important Reason

(64 2) /Usage/Reasons/Convenience

(64 42 1) /Usage/Reasons/Convenience/Convenient

(6 $\left.4 \begin{array}{l}2 \\ 2\end{array}\right)$ /Usage/Reasons/Convenience/Not Convenient

(643) /Usage/Reasons/Retrieval

(6 $\left.\begin{array}{llll}6 & 3 & 1\end{array}\right)$ /Usage/Reasons/Retrieval/Need Retrieval

(6 $4 \begin{array}{ll}3 & 3\end{array}$ ) $) /$ Usage/Reasons/Retrieval/Do Not Need Retrieval

(64 4) /Usage/ReasonsStaffing Problems

(645) /Usage/Reasons/New Versions

(646) /UsageReasons/Directed

(65) /Usage/Management

(6 5 1) 1 /Usage/Management/Improves

(6 5 2) /Usage/Management/Does Not Improve

(66) $/$ Usage/Teachers

(67) / Usage/SA

(6 8) /Usage/Principal

(69) /Usage/Time

(69 9 1) /Usage/Time/Up to Two Years

(69) $)$ /Usage/Time/Two Years or More

(6 10)/Usage/Degree of Use

(6 10 1)/Usage/Degree of Use/High

(6 10 2)/Usage/Degree of Use/Low

(611)/Usage/Confidence

(612)/Usage/High

(6 13)/Usage/Low

(6 14)/Usage/Resources

(6 14 1)/Usage/Resources/Satisfactory

(6 14 2)/Usage/Resources/Insufficient

(7) /Impact

(7 1) /Impact/Stress

(7 2) /Impact/Saves Time

(73) /Impact/Support

(7 4) $/$ Impact/Increase

(7 5) $/$ Impact/Decrease

(7 6) $/$ Impact/Reasons

(7 7) $/$ Impact/Yes

(7 8) $/$ Impact/No

(7 9) $/$ Impact/How

(7 10) /Impact/Happy

(7 11)/Impact/Unhappy

(7 12)/Impact/Workload

(8) /Own System 
(8 1) /Own System/Adequate

(8 2) /Own System/Inadequate

(9) /Improve SAMS

(9 1) /Improve SAMS/First Suggestion

(9 2 ) /Improve SAMS/Second Suggestion

(93) /Improve SAMS/Third Suggestion

(94) /Improve SAMS/ED Provide STRN No.

(95) /Improve SAMS/More Personal Information

(96) /Improve SAMS/Communication Primary Schools

(97) /Improve SAMS/Better Navigation

(9 8) /Improve SAMS/Environrnent

(9 9) /Improve SAMS/Special Staff

(9 10)/Improve SAMS/Resources

(9 11)/Improve SAMS/Increase

(9 12)/Improve SAMS/Decrease

(9 13)/Improve SAMS/ED Support

(9 14)/Improve SAMS/Incentive

(9 15) /Improve SAMS/More Appropriate Software

(9 16) /Improve SAMS/Upgrade Hardware

(9 17) /Improve SAMS/Draining

(9 18)/Improve SAMS/Speed

(9 19)/Improve SAMS/Support 